\title{
Caring, Relating, and Becoming: Child-Horse Relationships in Equestrian Leisure
}

\author{
Utsa Mukherjee
}

Dr. Utsa Mukherjee is an associate lecturer in childhood studies at Birkbeck University of London. He recently received his PhD in sociology from Royal Holloway University of London. His research is located at the intersections of childhood studies and leisure studies, with a focus on questions around children's social identities, agency, and materialities. Email: utsa.mukherjee.2015@live. rhul.ac.uk Twitter: @utsa_mukherjee

This article theorizes child-horse relations and explores the role of care therein. The existing body of research on human-animal relationships in the context of equestrian sport and leisure has for the most part eschewed children's narratives. Drawn from a wider project on British Indian children's everyday leisure, this article presents a case study of a child engaged in horse riding as a structured leisure activity. Using interview data with the child and her parents, the analysis demonstrates that child-equine care relationships are reciprocal and unfold within a wider set of social relationships or what I call "multispecies generational order."

Key words: child-horse relations; horse riding; equestrian leisure; care work; generational order
Humans have historically shared a complex set of relationships with their equine companions, especially in the realms of transport, warfare, sport, industry, and agriculture (Crossman \& Walsh, 2011; Forrest, 2016). Guided by the recent upsurge of interest in the relations between humans and nonhuman animals (see Bornemark, 2019), social research too has come alive to the ways in which humans and horses create shared meanings and influence each other's engagement with the world they cohabit. Such understandings are grounded in the context, for human-equine interactions derive from and unfold within specific historical and sociocultural settings. In this respect, equestrian sports and leisure offer an important opportunity to understand human-horse relationships as a social process. The growing body of literature around equestrian leisure has explored questions of social class (Coulter, 2014; Fletcher \& Dashper,

2013; Lenartowicz \& Jankowskic, 2014) and gender (Birke \& Brandt, 2009; Butler, 2013; Dashper, 2016; Plymoth, 2012) and offered a critique of the anthropocentric paradigm that sees horses as passive objects of human leisure (Dashper, 2018a, 2018b). In contrast to this paradigm, it has been argued that horses possess agency and are able to cocreate communication systems with their human companions that allow for intersubjective experiences to emerge (Brandt, 2004; Dashper, 2018a). Nonetheless, children's experiences and perspectives have remained at the margins of these narratives. This article presents empirical findings about a child's lived experiences of meaningful interactions with horses in spaces of equestrian leisure and illuminates how care is embedded in these processes. In doing so, it draws on two bodies of scholarship, namely human-nonhuman-animal studies (HAS) and the sociology of childhood. The discussion presented here contributes to both.

In the UK, equestrian activities form a key part of the commercial leisure scene and they are indeed integral to what has been described as Britain's "horse industry" (Department for Environment, Food, and Rural Affairs, 2004; Suggett, 1999). Equestrian leisure received significant public visibility during the 2012 London Olympics, where the British contingent achieved unprecedented success in equestrian sports. Since then, there has been a sharp increase in the number of young horse riders, as well as in net customer spending across horse-related goods and services in the country (British Equestrian Trade Association, 2015). The 2015 National Equestrian Survey in the UK found that horse riding as a leisure activity was the most popular horse-related activity in the country at 
$96 \%$, with most of the horse riders being between the ages of 25 and 44 followed by under 16s (British Equestrian Trade Association, 2015). Relatedly, a recent nationwide survey by Sport England (2018) found that 1.3\% of children under the age of 16 did horse riding at school while $2.4 \%$ did so outside of school. The limited spread of equestrian leisure among children points toward the financial barriers that still remain in accessing equestrian leisure: It is far more expensive and thus more class biased than many other leisure and sport activities available to children. As such, horse riding serves as a class marker (Coulter, 2014; Fletcher \& Dashper, 2013; Lenartowicz \& Jankowskic, 2014) that helps one to achieve social distinction; therefore, urban middle-class parents often make a conscious effort to encourage their children to take up equestrian leisure for its symbolic and cultural worth. Besides social class, equestrian leisure mediates an important gender dynamic (see Dashper, 2018a) as unlike many other sport and leisure activities it has no formal practice of sex-segregation and it is the only Olympic sports where men and women horse riders compete against each other in the same category at all levels. Apart from these questions of class and gender in horse riding, which have been looked into at length within social research, equestrian leisure also opens up an important analytical space to examine the various forms of interspecies interaction, communication, and participation that makes equestrian leisure possible in the first place. Studies that have addressed those dynamics of human-horse relations manifest in equestrian leisure have predominantly done so with respect to adult humans and horses, with the experiences of children in these settings remaining largely at the margins. In this article, the meanings and experiences of human-horse relations for children will be presented using a case study, and I will pay particular attention to how care is engendered in such relations. But before presenting the empirical material, it is important to clarify and harness key conceptual frameworks from both HAS and childhood studies, which will enable us to sketch out the processes and implications of interspecies interactions in a more-than-human-world.

\section{Nonhuman animals, childhoods, and "caring" in more-than-human worlds}

The shift in the conceptualization of horse from an automaton or a biological system with species-typical behaviour to a subject in their own right who participates in society and possesses feelings and perspectives of their own has flown from the wider domain of HAS (Bornemark, 2019). The interdisciplinary field of HAS in turn draws on both posthumanism and the animal rights literature: The former challenges anthropocentrism and draws attention to interspecies entanglements, while the later takes a normative stance about the treatment of animals and their place in society. In considering human-horse relations in equestrian leisure, in this article I draw mostly on posthuman frameworks and their overlap with the animal rights perspective. This new way of framing human-horse relations calls into question the dualism - and indeed the hierarchy - that is often constructed between humans, who are regarded as subjects, and animals, who are understood as objects (see Collard \& Gillespie, 2015). Instead, horses are understood as actors, that is, "beings that have the capacity to direct change," with subjectivities who "act in concert with other beings and things, including humans" (Collard \& Gillespie, 2015, p. 8). Bornemark (2019) notes that to

understand the horse ... as an interspecies cultural being ... means that it is not "one and the same thing" but different depending on its personal character ... Social sciences thus have to be broadened to ... examine power-relations where the animals are also treated as subjects. (p. 4)

Building on these insights, I will now locate the notion of care(-ing) within child-horse relations in a way that recognizes the intersections of animals, work, and care (Coulter, 2016a, 2019). I will then sketch the role of the child vis-à-vis care-ideas I will harness later in this article to theorize an interspecies approach to children's power relations that takes childhood studies beyond (human-centered) generationality to include what I call "multispecies generational orderings" of childhood. 
Care is a complex and multifaceted concept. Though it has been formulated in different ways within various intellectual frameworks, the most useful approaches for understanding the dynamics of "caring" in human-animal interactions are found in the works of Donna Haraway (2008) and María Puig de la Bellacasa (2012). Their newmaterial-feminist interventions offer a robust means to appreciate the significance of care and to reflect on what it means for humans to care for nonhuman others (Desai \& Smith, 2018; van Dooren, 2014). In more-than-human worlds where heterogeneous forms of life and matter are entangled and interdependent, Puig de la Bellacasa (2012) says, "to care about something, or for somebody, is inevitably to create relation" (p. 198). Though not all relations can be characterized as caring, none can endure or survive without care. In Puig de la Bellacasa's vision of care, care emerges as simultaneously an affective state, an ethical obligation, and a practical labour. Thus conceived, the "ethico-affective everyday practical doings" of care (p. 199) are significant for thinking and living in interdependent more-than-human worlds. Enlisting these ideas, I follow Kendra Coulter (2019) in defining care work as a "large cross-section of work involved in caring for others, physically and/or emotionally" (p. 22).

In a similar vein, Haraway (2008) invites us to think about multispecies living in terms of "becoming with," where species are consequent on a "subject- and object-shaping dance of encounters" (p. 4). As beings-in-encounter, species in the more-than-human world are participants in practices of becoming worldly in a way that can potentially gesture toward a just and peaceful autre-mondialization (Haraway, 2008). This process of multispecies "becoming with" inserts one into a "web of caring" (Haraway, 2008) where caring means "becoming subject to the unsettling obligation of curiosity, which requires knowing more at the end of the day than at the beginning" (p. 36). In underlining these notions of caring, both Puig de la Bellacasa and Haraway are attentive to the fact that species meet within macrogeographies inscribed by postindustrial capitalism, gender, race, and class. In other words, the caring embedded in multispecies coconstitution and worlding is underpinned by the material-semiotic interplay that shapes their becomings (van Dooren et al., 2016). Although these modes of thinking create affordances for understanding nonhuman animals as subjects, they fall short of robustly identifying and comprehensively theorizing the care work these nonhuman animals carry out for themselves, for other animals, and for humans (see Coulter, 2016b). If we are to push beyond a human-focused idea of caregiving and of social justice and begin to unpack the reciprocal traffic that characterizes care in human-animal interactions, we have to first interrogate the intersections of animals and (care) work (Coulter, 2016a, 2016b).

Nonhuman animals, whether in the wild or on a farm or living as companion species with humans at home, are sentient beings with feelings, perspectives, and experiences of their own. They also carry out different kinds of work in different contexts, but as Coulter (2016a) points out, "animals' own forms of caregiving are rarely recognized as a kind of care work" (p. 200). She goes on to argue that we need to recognize these forms of labour carried out by animals as work. For instance, many companion animals in the domestic space are not only beneficiaries of care work and social reproductive labour carried out by humans for them, but they also perform "voluntary work" (Coulter, 2016b) for humans in the form of informal care work such as emotional support, interactions, and touch. Further, the life-sustaining labour that animals in the wild do is underpinned by informal care work for their young ones and communities. This kind of "subsistence work" (Coulter, 2016b) carried out by animals is often impeded by a range of human actions, including construction of physical infrastructure, leisure pursuits (such as hunting), and anthropogenic climate change, among others. Finally, animals-such as those on farms, racecourses, and in laboratories-have to do work that is mandated by humans and which largely serves the needs and wants of humans (Coulter, 2016b). As animals are increasingly being used by humans for therapeutic (e.g., equine-assisted therapies) and service work (such as that carried out by guide dogs), the labour animals do in these contexts requires care work. This kind of care work that animals do for humans in the context of human-mandated work arrangements, Coulter (2016b) writes, "is psychologically and emotionally challenging for animals, and they are required to suppress their personal feelings, reactions, and instincts in order to behave 
in the proper way regardless of what is going on around them" (pp. 204-205). Considering the care work that animals do for themselves as well as for humans offers a springboard into understanding the fact that nonhuman animals are subjects in their own right who contribute to human society and to the reproduction of ecosystems in multiple ways (see Coulter, 2016a). Furthermore, drawing on feminist political economy and cognitive ethology scholarship, Coulter (2019) argues that horses on farms and in other human-controlled spaces have "work lives" wherein they carry out a range of work-which is simultaneously intellectual and embodied-although they are not remunerated for their work in a conventional sense. Coulter's (2019, 2016a, 2016b) scholarship on horses' work lives and her conceptual vocabulary for understanding nonhuman animal's care work, described above, are useful in unpacking the processes of caring that underpin child-equine relations.

Just as the care work animals do has long been unrecognized, the care work children carry out within their lived geographies has hardly ever been explicitly valued as work. This stems from the dominant framing of childhood as a period of dependency and thus children are seen only as recipients of care, where such caring responsibilities lie with the family and at times the state. Recent developments in childhood studies have challenged these ideas and have instead drawn our attention to the range of informal, everyday, and reciprocal care work that children carry out for parents, siblings, kin, carers, friends, neighbours, and others both inside and outside the home (Eldén, 2016; Luttrell, 2013; Morrow, 2008; Webster, 2018). Studies have also pointed out that children contribute to the care of family pets, often treating such companion species as members of their family (Mason \& Tipper, 2008; Morrow, 1998; Tipper, 2011). The growing scholarship on children's relationships with family companion animals (Mason \& Tipper, 2008; Morrow, 1998; Rautio \& Leinonen, 2018; Tipper, 2011) has inaugurated fresh conversations within childhood studies about child-animal relationality and prompted researchers to rethink the conceptual frames currently used in the field. Nonetheless, these studies have located the relationships of care with nonhuman animals that children construct and nurture largely within the confines of the home, the school, and occasionally the neighbourhood. The entanglement of the human child and nonhuman animals in leisure activities organized and paid for outside of school is conspicuously absent from the current body of scholarship. Equestrian leisure in that respect offers a crucial opportunity to reshape our understanding of child-animal relations in contexts beyond the home or the school and involving a nonhuman animal, the horse, which is physically distinguished from common family pets like dogs, cats, or hamsters or from species like rats, worms, and insects that children encounter in their everyday geographies. As Keaveney (2008) points out, horses display formidable differences from common domestic nonhuman co-species, and therefore their relations with humans demonstrate a unique "kind of human-animal relationship, one in which the line between [nonhuman] animal and human is not quite so blurred" (p. 444). It is this alterity that can help us learn more about multispecies relationality and caring in the Anthropocene using children's cases as the point of entry.

Based on the discussion presented above, it can be argued that children and nonhuman animals-especially horses-are two important social groups who perform care work for others, but in both cases their care work is hardly explicitly recognized or valued as work. Therefore, shared spaces in which children and horses interact create opportunities for us to harness those lived experiences and reshape our current understanding, not only of human-child-horse relationality, but also of the dynamics of care work itself. At the same time, it bears pointing out that the care work involving human children and horses implicates power relationships and cultural legacies which need to be seriously considered. As Coulter (2019) reminds us, "horses may indeed partner with us in a range of tasks and exercise agency, but the situation is not one of absolute equals" (p. 21). Paying due attention to these structural dynamics, in what follows I outline the methods through which the empirical materials for this article were generated. Drawing on a case-study approach to qualitative research, I elaborate the case of 12-yearold Koel, who does horse riding as a structured leisure activity. 


\section{Studying child-horse relations: A case-study approach}

The empirical material presented in this article is based on a case study of a 12-year-old child named Koel (a pseudonym) who engages in horse riding once a week as a structured leisure pursuit, or what is often described as an "enrichment activity" (Vincent \& Ball, 2007). A case study "is the study of the particularity and complexity of a single case" (Stake, 1995, p. xi). Koel's case, as elaborated in this article, is drawn from a wider qualitative project conducted by the author during 2017-2018 which investigated the interplay between social identities and leisure practices in the everyday lives of British Indian children aged 8 to 12 growing up in the contemporary UK. The families in the study were based in and around London, and all the parents (except for housewives) were high-earning professionals in the knowledge-based economy. In this article, the case of Koel has been set apart for detailed study. Her case was selected for detailed study in this article because, unlike other children in the wider project, she was involved in a structured activity—namely horse riding — that revolved around a nonhuman animal (the horse). Other children did sports, swimming, and performative arts that involved human-material entanglements without direct participation of animals. Indeed, horse riding did not come across as a popular structured leisure activity in the participating families. This is because riding classes are relatively expensive (a onehour lesson can cost around £100) and there are a limited number of training facilities available in London. As will be explained below, Koel was on a waiting list for five years before she could start at the riding school. Nevertheless, her case needs to be heard and understood because of its relative uniqueness. To date the studies on horse-human relationality and care work have not systematically attended to the experiences of younger children. In that sense, Koel's case offers an important entry point to contribute to the scholarly work on child-horse relations. It is a springboard that can uncover underlying processes of theoretical import missing from both childhood studies and the HAS. In embracing the case-study approach, I will now discuss its controversial status within the folds of social research and its limitations. Nonetheless, I argue that there is much value to be accrued from a case study of an area of research which is particularly underdeveloped.

As indicated previously, case studies are in-depth investigations of particular cases. In this article, I am positing case study not as a "method" but as an "approach" which can use different sets of methods "to reconstruct and analyze a case from a sociological perspective" (Hamel et al., 1993, p. 1). The critics of case study argue that given its reliance on a singular event or person, case studies produce nongeneralizable theories and suffer from biased case-selection (see Gerring, 2007). On the other hand, advocates of this approach point out that no case, however carefully selected, can be truly "representative," and that such criticisms are therefore misdirected (Yin, 2003). Moreover, Yin (2003) posits that although a researcher cannot generalize the insights of a case study to other cases, they can generalize it to theory. Taking Yin's (2003) argument as my point of departure, I will now elaborate on how I conducted Koel's case study, including the method of data analysis.

Koel's family was recruited to the study from a Facebook group that catered to Indian families in London where I canvassed for participants and Koel's mother contacted me to express her interest. It was explicitly stated in the study poster posted to that Facebook group that participation in the study would be voluntary and no incentive was offered. During my study visit to Koel's family home, I presented Koel's mother, Aparna, and her father, Sumit, with information sheets, and they also filled in a consent form for themselves and their child to take part in the study. Koel was given an age-appropriate information booklet that described the study in simpler language and told her that she was free to decide for herself if she wanted to take part or not. It was further stressed that she was entitled to not answer any question or to withdraw from the study without giving any reason. She provided written as well as verbal consent for her own participation.

I conducted semistructured narrative interviews to collect data from Koel and her parents. Separate one-to-one interviews were conducted with Koel, Sumit, and Aparna. During the interview, I asked open-ended questions to 
Koel about her everyday life and her experiences of the various leisure activities she takes part in. Similarly, with the parents, I took a narrative approach and asked questions about their occupation, life trajectories, everyday life, parenting practices, and, most importantly, their views about Koel's leisure engagements. I interviewed both Koel and her parents for two reasons. First, we know from existing studies that parents influence their children's leisure choices and that children's enrollment into multiple structured activities and the activities' perceived benefits for children have made them an integral aspect of the "good parenting" discourse in middle-class families (Jeanes \& Magee, 2011). Second, most of these studies rely on parents' narratives alone and therefore a research design that accommodates and juxtaposes both parents' and children's narratives was deemed most suitable to gain a deeper understanding of the social processes that underpin children's structured leisure choices and lived experiences. The data gathered through these interviews was audio-recorded with the explicit consent of the participants and then transcribed verbatim. The data was then interpreted using narrative analysis. I read each transcript multiple times and extracted the key points, which I then read in relation to the life stories of the participants and their spatial-temporal contexts. As Griffin and May (2018) rightly point out, narratives produced through interviews do not give us direct access to what "really" happened or to subjects' underlying motives, but they are indispensable for conveying how experiences are subjectively understood and reconstructed by subjects once they have occurred.

In presenting my analysis of these narratives, I am aware of thelimitations of this (human) case study. A comprehensive understanding of child-horse relations requires insights into both the child's and the horse's perspectives. Although accessing the horse's feelings and experiences is impossible for social researchers (Bornemark, 2019), observation data of real-time interactions, which my study lacks, could have been useful. Nevertheless, human interpretations and narratives about horses found in the accounts of Koel and her parents reveal important clues about how horses are constructed as objects/subjects of knowledge-and how those constructions manifest forms of power relations (Palmer, 2017). In the rest of this article, I draw on Koel's and her parents' narratives to explore, describe, and theorize different dimensions of the child-horse relation within the time-spaces of equestrian leisure and unpack the processes of care therein.

\section{The process of (classed) world making: Entering the "horse world"}

Koel is a 12-year-old girl who lives in London with her parents, Sumit and Aparna. Both Sumit and Aparna grew up in middle-class families in urban India. They attended fee-paying English-medium schools and then completed their undergraduate education in India. After marriage they moved to Germany to study for their MBAs. It was there that Koel was born. When Koel was three months old, Sumit got a job in the UK and the entire family migrated with him to the south of England. They have now lived in the UK for 12 years and hold British citizenship. Much like other middle-class children in London, Koel has a busy schedule of organized and paid-for leisure activities that she attends every week. Her catalogue of structured leisure activities includes swimming, tennis, netball, piano, and horse riding. As previous scholars have argued, middle-class children are increasingly being enrolled in a plethora of organized leisure lessons by their parents at an ever-younger age (Lareau, 2011; Nelson, 2010; Pugh, 2009; Vincent \& Ball, 2007). These studies reveal that parents treat their investment in children's leisure activities as a means of shaping their children's future career trajectories by equipping them with key skills and social networks manifested in "résumés sparkling with extracurricular" achievements (Nelson, 2010, p. 25; also see Pugh, 2009).

Reflecting this wider pattern of middle-class discourses of parenting, Sumit and Aparna have enrolled Koel in multiple structured leisure lessons. They think that these lessons will equip her with key skills that will supplement the social advantages cornered through her private-school education. They also possess the financial and cultural resources to play the leisure market at will, and they devote a great deal of money, time, and effort at supporting their child's leisure activities. This aspect is reinforced by the fact that Aparna, an MBA graduate with many years 
of experience in the knowledge-industry, decided to give up her career soon after Koel was born because of her parenting responsibilities. Her life now revolves around Koel's daily schedule. Indeed, Koel's multiple leisure engagements create a great deal of logistical labour in terms of accompanying her to these places, most of which is done by Aparna, not Sumit.

Aparna grew up in India. Her parents wanted her to learn dancing and singing through after-school lessons, but she refused. She preferred outdoor play with her neighbourhood friends. The outdoor play culture in the neighbourhood is largely absent in the UK today. It has declined radically over the years because of dominant risk perceptions of "stranger danger" for unsupervised younger children (see Scott et al., 1998). Aparna says, "My daughter is very different; she is very lonely here. As such, the culture of playing outside on the road is missing." It is in this context that her encouragement for Koel to take up multiple organized leisure pursuits garners added urgency. Nonetheless, the activities she has shortlisted for Koel bear the mark of social class processes. For instance, she had put Koel on a waiting list for horse-riding lessons five years before Koel even got to try a taster session. Although Koel got to decide whether to continue or jettison horse riding, the very choice of horse riding as a leisure activity in the urban spaces of London speaks of the class distinctions it brings. But where previous studies on children's structured leisure (see Lareau, 2011; Vincent \& Ball, 2007) stop at the class implications alone, it is important to probe the posthuman geographies of these leisure spaces.

While recalling the way Koel started off with horse riding, Aparna explained:

When I went there [the horse-riding school], I heard that they wanted to make the children responsible. So, they're not only teaching horse riding, they're teaching how to clean the boots, how to clean the stable, and then literally mucking the poo, the horseshit, every day. So, I thought that was a tremendous test of character and personality. And my daughter is a very delicate person and I didn't think that she'd do it, but she doesn't mind. That was a revelation!

Aparna here stresses not only the technical aspects of horse riding but the associated aspects of the "horse world" (Dashper, 2018a). The horse world denotes an entanglement, not only of horses and humans, but also of the materialities of the stable, as well as the sights, sounds, touch, and smells that constitute it. The discourse of character building and personality that Aparna draws on comports with the findings of previous scholars (Knight, 2005; Theodossopoulos, 2005) who noticed that adult-human actors often take an instrumental view of nonhuman animals' role in society. The cleaning of the boots and stables is not seen here as care work but as a conduit for testing the child's "character and personality." Relatedly, sociologists of childhood (Morrow, 1998; Rautio \& Leinonen, 2018) have critiqued the tendency of adults, often informed by developmental psychology, to position children's care work for companion species such as family pets as a kind of role rehearsal for future adult responsibilities, thereby rendering the latter as pedagogical tools bereft of subjectivity. For Aparna, the horseand the horse's work life-is immaterial. The horse serves a purpose for Koel-not the other way around. Aparna deems it a "revelation" that Koel—“a very delicate person" - is cleaning the stables and "mucking the [horse] poo." Therein lie the social implications of Koel's entry into the horse world: the horse-human "contact zone" (Haraway, 2008) emerges as a world-making entanglement, a process of mutual coconstitution and becoming. The horsehuman Koel is different. She cleans the stables and mucks the horse poo and enjoys being around horses. This illustrates her "becoming with" horses where her immersion in the horse world has implications for her life outside it. Aparna further points out:

[Koel] is not usually very animal friendly, but when she went and she saw a horse, she immediately started petting it and stroking it and she just took to the horse like a fish to water and she absolutely adores it. 
Aparna's observations demonstrate the tactile and sensorial dimensions of the multispecies "contact zone" created between Koel and the horse. In asking the question "Whom and what do I touch when I touch my dog?" (p. 35) Haraway (2008) points out that touch ramifies and shapes accountability as it it peppers its partners with attachment sites for world making" (p. 36). Although Aparna is reducing the horse to a species representative and not recognizing the horse's subjectivity as such, her narrative can be read from Haraway's perspective to illustrate how Koel's acts of touching and stroking the horse are "peppering" both of them with such sites for co-being and becoming. However, it is important to note here that the horse is at "work" in the riding school. Drawing on Coulter (2016a, 2016b, 2019), it can be argued that while the horse is engaging with Koel—that is, allowing Koel to pet and stroke them without resisting-they are performing a range of work that needs to be recognized as such. First, a horse is not a biological system alone but a subject with perspectives, feelings, and personality of their own, and they do have "work lives" (Bornemark, 2019; Coulter, 2019). When talking to me about horse riding, Koel shared experiences of initial nervousness about horse riding-she was concerned about how the horse would behave and how she should react. We will investigate Koel's narrative later, but suffice it to say that she was presumably anxious in her first contact with the horse she now describes as "my horse." Koel's horse must have perceived Koel's anxiousness but still remained calm and allowed Koel to pet and stroke them. In that sense, Koel's horse was performing what Hochschild (1983) calls "emotional labour" as part of their job as a riding-horse-ina-stable. The horse's emotional labour plays out in concert with emotional work, that is, the internal regulation and management of emotions on the part of that horse (see Coulter, 2019). In other words, we must recognize the range of work-including the informal care work-that "Koel's horse" carried out, which created the space for Koel to extend her care work toward "her horse." Second, by marking this specific horse as her horse, Koel is symbolically establishing the fact that horses are owned and controlled by humans and therefore the power relationship between the two is never of absolute equals. Moreover, Koel was already paired with this horse by the instructor in the riding school, which signifies another set of power relations in which Koel is situated besides her relationship with her parents. Hence, the power relations circumscribing Koel's leisure identity are layered and multifaceted. Coulter (2016a, 2019) argues that from the standpoint of horses, work is experienced along a continuum of suffering and enjoyment. We simply do not know where on this continuum Koel's horse's informal care work for Koel fits. But we have a means to know what Koel feels about her informal care work toward her horse, as I will now elaborate.

\section{Caring, communicating, and becoming in the horse world}

While talking to me about her everyday leisure repertoire, Koel reported the following:

Koel: Of all the activities I do after school, horse riding is my favourite.

Interviewer: Why is it your favourite?

Koel: Because I really like being around horses. I like my horse-riding lessons.

As I asked follow-up questions about what sets equestrian leisure apart for her, Koel explained the structure of this leisure activity and located her rationale therein. She told me the following:

One week we ride. The next week, we [fellow riders in the riding school] clean the stables and get to spend time with the horse. My horse is really nice. I like the week where we clean the stables.

The riding school in London that Koel attends operates a weekly training cycle, where one-week participants learn how to ride horses and the next week they clean the stables and look after their horses. This weekly cycle affords Koel the opportunity to engage with the different actors of the horse world, including fellow riders, and with the 
materiality of the stable. This practice is different from the notion of the "stable girl" found in Finland where girls of Koel's age and older volunteer at local stables several times a week to take care of horses (see Ojanen, 2012). While describing her experiences of engaging with the horse world, Koel says that she prefers the week where she gets to clean the stable more than the day of riding. That way, she gets to immerse herself in the material environs of the stable and to familiarize herself with the texture of hay and straw, the smell of "horse poo," and the touch of her horse, understood here not as an automaton but as co-species or partner.

It is important to note the multiple generational relationships in which Koel's equestrian leisure is embedded, and indeed through which she exercises her agency. In the excerpt above, Koel refers to her fellow riders as "we," with whom she shares the stable alongside the horses. Further discussions with Koel revealed that her group of fellow riders is mixed sex and mixed age. In her riding school, the instructors set the scene in terms of grouping the riders together according to riding abilities irrespective of age or gender. This creates a space-unlike all other leisure activities that Koel does-where people across age groups are brought together around the common purpose of riding horses and cleaning the stables.

Moreover, by singling out the act of cleaning the stables and looking after "her" horse, Koel demonstrates how care work underpins child-animal relations in equestrian leisure settings. Her care work-encompassing both emotional and physical dimensions - is brought to the fore in the following description she offered regarding her preferred act of cleaning the stables:

So, if you have to clean their [horses'] hooves you have to tap them. And then they will lift their hooves for cleaning ... They are really nice animals and they are nice to be around.

As discussed earlier, Koel was anxious about horses in the beginning, but her initial positive experience of "stroking" and "petting" facilitated her sense of comfort with horses. Earlier in this article, I argued-drawing on Coulter (2019) — that Koel's horse was at work when Koel attempted to pet and stroke them: the horse was doing emotional work to regulate their own emotions and present a calm demeanour that suited Koel. The horse, in a sense, was caring for Koel. Although we know that Koel enjoys her care work, we have no way of discerning the consequences of that interaction for the horse. In the quotation above, Koel outlines two other interrelated processes. First, Koel's fond memory of cleaning the hooves of horses underlines her ethical-affective, practical labour of care (Puig de la Bellacasa, 2012). The notion of "nice animals" and a general sense of fondness toward "her" horse is evident. She is therefore emotionally at stake and is being affected by her interaction with the nonhuman other. Of course, the specific tasks she carried out-like cleaning the stables-were learned in interaction with the instructor and her fellow riders; nonetheless, they are underpinned by care work that encompasses her physical effort of using brooms to clear the detritus and make the stable more livable for the horses.

Second, Koel lays bare the process through which she and her horse cocreate a nonverbal and embodied communication system wherein a tap by Koel on a specific part of the horse's body and in a certain manner makes the horse lift their hooves, which in turn enables Koel to clean them. The two-way process of tapping the horse's body and lifting of the hooves, carried out by Koel and the horse respectively, demonstrates that child-animal relation is a reciprocal process. Koel has learned to "speak horse" (Birke, 2007) from her instructor and fellow riders, as shown by her reported ability to understand horses' bodily gestures and sounds. Her horse in turn interprets the meanings of her touches and gestures. It is through this collaboration, communication, and reciprocity that multispecies relationality is lived out. The establishment of this human-animal system of communication is noteworthy; Brandt (2004) argues that deprivileging the human emphasis on spoken language "opens the door for investigation of the ways in which animals and humans alike use a variety of modes of communication to convey subjectivity" (p. 314). In a similar fashion, Koel's description of hoof cleaning, which is underpinned by her care 
work, points to the nonverbal and embodied basis of child-horse interaction.

\section{Conclusion}

In this article I have drawn on childhood studies and HAS to unpack child-horse relations in the context of equestrian leisure. Acknowledging the limitations and benefits of the case study approach, I have argued that indepth exploration of a case study like Koel's can serve as a springboard to begin systematic work on the role of care work in child-horse relations. The empirical material presented throughout this article has posited key points of interest, which I will now summarize and build upon.

Care is a complex and multifaceted concept. Consequently, the imbrications of care work in child-horse relations go beyond the human actor alone. Building on Coulter's (2016a, 2016b, 2019) scholarship on nonhuman animals' work, I have indicated how, at various points in Koel's interaction with her horse, the care work performed was not exclusive to Koel. On the contrary, the horse cooperated, managed their own emotions, and stayed calm to reassure Koel and help create the bond that Koel cherishes. It can be argued that the care work performed by the horse is integral to their work life in the riding school. Although the implications of that care work for Koel can be identified from her narrative, the horse's own experiences of receiving and providing informal care work cannot be known. Even in shared spaces of child-animal commingling and becoming, ethico-political questions remain as to the bodily appropriation of the horses in equestrian leisure spaces that makes riding and companionship possible in the first place. In other words, understanding the care work in child-animal relations depends on serious consideration of the power relations across species boundaries within which such shared spaces are produced. In this article I have pointed out some of those questions, but they need to be unpacked further in future studies.

Koel's relationship with her horse is situated within wider webs of other social relations involving her parents, her riding instructor, and her fellow learners. Koel's mother, Aparna, plays an active role in shaping Koel's leisure repertoire. For instance, sending Koel to horse riding was her choice. Aparna also undertakes the activity management labour in terms of driving her to and from lessons. While at the riding school, the instructor assigns Koel her horse and puts her in specific groups based on her ability. Koel then learns about horse riding and care from her instructor as well as from her fellow riders in the mixed-sex, mixed-age group. We also know from Ojanen (2012) that social hierarchies are constructed among human actors in the stable based on age and experience. In this way, these inter- and intragenerational relations - child/parent, child/instructor, child/fellow-learner-inform Koel's equestrian leisure geographies. The existing theoretical lens of "generational order" (Alanen, 2001, 2011) is useful in identifying the various reciprocal generational relations Koel is part of. But the anthropocentrism of the generational-order lens falls short of acknowledging and analyzing children's power relations and structural positioning across the species boundary. Therefore, I posit the notion of "multispecies generational order" as a hybrid lens that can bring within a single framework children's intergenerational as well as interspecies positioning in particular time-spaces and draw out the implications of these relative locations for children's lived experiences and agency. Seen in this light, the reciprocal care work carried out by Koel and her horse within the time-spaces of equestrian leisure is one set of relations that is in turn embedded in a wider set of (human) generational relations. The meaning and implication of child-horse relations in this context is informed by and distributed along these power relations and relative positions of humans and nonhumans. This lens of multispecies generational order enables us to probe child-animal relationality without losing sight of the dynamic human generational structures in which children are socially positioned in contradistinction to adults and other children. 


\section{References}

Alanen, L. (2001). Childhood as a generational condition: Children's daily life in a central Finland town. In L. Alanen \& B. Mayall (Eds.), Conceptualizing child-adult relations (pp. 129-143). Falmer Press.

Alanen, L. (2011). Generational order. In J. Qvortrup, W. A. Corsaro, \& M. Honig (Eds.), The Palgrave handbook of childhood studies (pp. 159-174). Palgrave Macmillan.

Birke, L. (2007). "Learning to speak horse": The culture of "natural horsemanship." Society \& Animals, 15(3), 217-239. https://psycnet. apa.org/doi/10.1163/156853007X217177

Birke, L., \& Brandt, K. (2009). Mutual corporeality: Gender and human/horse relationships. Women's Studies International Forum, 32(3), 189-197. https://doi.org/10.1016/j.wsif.2009.05.015

Bornemark, J. (2019). Introduction: Subjectivity and ethical questions in an equestrian world in transformation. In J. Bornemark, P. Andersson, \& U. E. von Essen (Eds.), Equine cultures in transition: Ethical questions (pp. 1-13). Routledge.

Brandt, K. (2004). A language of their own: An interactionist approach to human-horse communication. Society \& Animals, 12(4), 299-316. https://doi.org/10.1163/1568530043068010

British Equestrian Trade Association. (2015). National equestrian survey 2015. Author.

Butler, D. (2013). Not a job for "girly-girls": Horseracing, gender, and work identities. Sport in Society, 16(10), 1309-1325. https://doi.or $\mathrm{g} / 10.1080 / 17430437.2013 .821250$

Collard, R., \& Gillespie, K. (2015). Introduction. In K. Gillespie \& R. Collard (Eds.), Critical animal geographies: Politics, intersections, and hierarchies in a multispecies world (pp. 1-16). Routledge.

Coulter, K. (2014). Herds and hierarchies: Class, nature, and the social construction of horses in equestrian culture. Society \& Animals, 22(2), 135-152. https://doi.org/10.1163/15685306-12341253

Coulter, K. (2016a). Beyond human to humane: A multispecies analysis of care work, its repression, and its potential. Studies in Social Justice, 10(2), 199-219. https://doi.org/10.26522/ssj.v10i2.1350

Coulter, K. (2016b). Animals, work, and the promise of interspecies solidarity. Palgrave Macmillan.

Coulter, K. (2019). Horses' labour and work-lives: New intellectual and ethical directions. In J. Bornemark, P. Andersson, \& U. E. von Essen (Eds.), Equine cultures in transition: Ethical questions (pp. 17-31). Routledge.

Crossman, G. K., \& Walsh, R. (2011). The changing role of the horse: From beast of burden to partner in sport and recreation. The International Journal of Sport and Society, 2(2), 95-110.

Dashper, K. (2016). Strong, active women: (Re)doing rural femininity through equestrian sport and leisure. Ethnography, 17(3), 350-368. https://doi.org/10.11772F1466138115609379

Dashper, K. (2018a). Human-animal relationships in equestrian sport and leisure. Routledge.

Dashper, K. (2018b). Moving beyond anthropocentrism in leisure research: Multispecies perspectives. Annals of Leisure Research, 22(2), 133-139. https://doi.org/10.1080/11745398.2018.1478738

Department for Environment, Food and Rural Affairs. (2004). A report of research on the horse industry in Great Britain. https://assets. publishing.service.gov.uk/government/uploads/system/uploads/attachment data/file/69259/pb9255-bhic-report-040318.pdf

Desai, S., \& Smith, H. (2018). Kinship across species: Learning to care for nonhuman others. Feminist Review, 118(1), 41-60. https://doi. org/10.10572Fs41305-018-0104-0

Eldén, S. (2016). An ordinary complexity of care: Moving beyond "the family" in research with children. Families, Relationships, and Societies, 5(2), 175-192. https://doi.org/10.1332/204674315X14285937023932 
Fletcher, T., \& Dashper, K. (2013). "Bring on the dancing horses!": Ambivalence and class obsession within British media reports of the dressage at London 2012. Sociological Research Online, 18(2). https://doi.org/10.51532Fsro.3040

Forrest, S. (2016). The age of the horse: An equine journey through human history. Atlantic Monthly Press.

Gerring, J. (2007). Case study research: Principles and practices. Cambridge University Press.

Griffin, A., \& May, V. (2018). Narrative analysis and interpretative phenomenological analysis. In C. Seale (Ed.), Researching culture and society (pp. 511-532). SAGE.

Hamel, J., Dufour, S., \& Fortin, D. (1993). Case study methods. SAGE.

Haraway, D. J. (2008). When species meet. University of Minnesota Press.

Keaveney, S. M. (2008). Equines and their human companions. Journal of Business Research, 61(5), 444-454. https://doi.org/10.1016/j. jbusres.2007.07.017

Hochschild, A. R. (1983). The managed heart: Commercialization of human feeling. University of California Press.

Jeanes, R., \& Magee, J. (2011). Children, youth and leisure: Editors' introduction. In R. Jeanes \& J. Magee (Eds.), Children, youth and leisure (pp. v-xi). Leisure Studies Association.

Knight, J. (2005). Introduction. In J. Knight (Ed.), Animals in person: Cultural perspectives on human-animal intimacies (pp. 1-13). Berg.

Lareau, A. (2011). Unequal childhoods: Class, race, and family life ( $2^{\text {nd }}$ ed.). University of California Press.

Lenartowicz, M., \& Jankowskic, K. W. (2014). Reconstructing class sport practices in post-communist Poland. Physical Culture and Sport, 63(1), 12-19. https://doi.org/10.2478/pcssr-2014-0018

Luttrell, W. (2013). Children's counter-narratives of care: Towards educational justice. Children \& Society, 27(4), 295-308. https://doi. org/10.1111/chso. 12033

Mason, J., \& Tipper, B. (2008). Being related: How children define and create kinship. Childhood, 15(4), 441-460. https://doi. org/10.11772F0907568208097201

Morrow, V. (1998). My animals and other family: Children's perspectives on their relationships with companion animals. Anthrozoös, 11(4), 218-226. https://doi.org/10.2752/089279398787000526

Morrow, V. (2008). Responsible children and children's responsibilities? Sibling caretaking and babysitting by school-age children. In J. Bridgeman, H. Keating, \& C. Lind (Eds.), Responsibility, law and the family (pp. 105-124). Ashgate.

Nelson, M. K. (2010). Parenting out of control: Anxious parents in uncertain times. New York University Press.

Ojanen, K. (2012). "You became someone" social hierarchies in girls' communities at riding stables. Young, 20(2), 137-156. https://doi. org/10.11772F110330881202000202

Palmer, C. (2017). "Taming the wild profusion of existing things"? A study of Foucault, power, and human/animal relationships. In M. Chrulew \& D. J. Wadiwel (Eds.), Foucault and animals (pp. 107-131). Brill.

Plymoth, B. (2012). Gender in equestrian sports: An issue of difference and equality. Sport in Society, 15(3), 335-348. https://doi.org/10. $\underline{1080 / 17430437.2012 .653204}$

Pugh, A. J. (2009). Longing and belonging: Parents, children, and consumer culture. University of California Press.

Puig de la Bellacasa, M. (2012). "Nothing comes without its world": Thinking with care. Sociological Review, 60(2), 197-216. https://doi. org/10.11112Fj.1467-954X.2012.02070.x

Rautio, P., \& Leinonen, R-M. (2018). Hamsters and children: The sidekick family members? Paper presented at "Childhood and Materiality," University of Jyväskylä, Finland, May 7-9. 
Scott, S., Jackson, S., \& Backett-Milburn, K. (1998). Swings and roundabouts: Risk anxiety and the everyday worlds of children. Sociology, 32(4), 689-705. https://doi.org/10.11772F0038038598032004004

Sport England. (2018). Active lives children and young people survey: Academic year 2017/18. https://www.sportengland.org/activelives/

Stake, R. E. (1995). The art of case study research. SAGE.

Suggett, R. H. G. (1999). Horses and the rural economy in the United Kingdom. Equine Veterinary Journal, 31(1), 31-37. https://doi. org/10.1111/j.2042-3306.1999.tb05153.x

Theodossopoulos, D. (2005). Care, order, and usefulness: The context of the human-animal relationship in a Greek island community. In J. Knight (Ed.), Animals in person: Cultural perspectives on human-animal intimacies (pp. 15-35). Berg.

Tipper, B. (2011). "A dog who I know quite well": Everyday relationships between children and animals. Children's Geographies, 9(2), 145-165. https://doi.org/10.1080/14733285.2011.562378

van Dooren, T. (2014). Care. Environmental Humanities, 5, 291-294. https://environmentalhumanities.org/arch/vol5/5.18.pdf

van Dooren, T., Kirksey, E., \& Münster, U. (2016). Multispecies studies: Cultivating arts of attentiveness. Environmental Humanities, 8(1), 1-23. https://doi.org/10.1215/22011919-3527695

Vincent, C., \& Ball, S. J. (2007). "Making up" the middle-class child: Families, activities, and class dispositions. Sociology, 41(6), 10611077. https://doi.org/10.11772F0038038507082315

Webster, M. (2018). Siblings' caring roles in families with a child with epilepsy. Sociology of Health \& Illness, 40(1), 204-217. https://doi. org/10.1111/1467-9566.12627

Yin, R. K. (2003). Case study research: Design and methods (3 $3^{\text {rd }}$ ed.). SAGE. 